\title{
The angiogenic factor midkine is regulated by dexamethasone and retinoic acid during alveolarization and in alveolar epithelial cells Huayan Zhang1, Samuel J Garber ${ }^{1}$, Zheng Cui ${ }^{1}$, Joseph P Foley ${ }^{1}$, Gopi S Mohan¹, Minesh Jobanputra1, Feige Kaplan², Neil B Sweezey ${ }^{3}$, Linda W Gonzales ${ }^{1}$ and Rashmin C Savani*1,4
}

Address: ${ }^{1}$ Division of Neonatology, Department of Pediatrics, Children's Hospital of Philadelphia, University of Pennsylvania School of Medicine, Philadelphia, PA, USA, ${ }^{2}$ Departments of Human Genetics and Pediatrics, McGill University, Montreal, Canada, ${ }^{3}$ Division of Respiratory Medicine, Departments of Pediatrics and Physiology, The Hospital for Sick Children, University of Toronto, Toronto, Canada and ${ }^{4}$ Divisions of Pulmonary \& Vascular Biology and Neonatal-Perinatal Medicine, Department of Pediatrics, University of Texas Southwestern Medical Center, Dallas, TX, USA

Email: Huayan Zhang - zhangh@email.chop.edu; Samuel J Garber - garbers@email.chop.edu; Zheng Cui - cuipenn@gmail.com; Joseph P Foley - joseph.2.foley@gsk.com; Gopi S Mohan - gopi.mohan@gmail.com; Minesh Jobanputra - mineshjobanputra@hotmail.com; Feige Kaplan - feige.kaplan@mcgill.ca; Neil B Sweezey - neil.sweezey@sickkids.ca; Linda W Gonzales - GONZALESL@email.chop.edu; Rashmin C Savani* - rashmin.savani@utsouthwestern.edu

* Corresponding author

Published: 21 August 2009

Respiratory Research 2009, 10:77 doi:10.1186/1465-9921-10-77
Received: II January 2009

Accepted: 21 August 2009

This article is available from: http://respiratory-research.com/content//0/I/77

(C) 2009 Zhang et al; licensee BioMed Central Ltd.

This is an Open Access article distributed under the terms of the Creative Commons Attribution License (http://creativecommons.org/licenses/by/2.0), which permits unrestricted use, distribution, and reproduction in any medium, provided the original work is properly cited.

\begin{abstract}
Background: A precise balance exists between the actions of endogenous glucocorticoids (GC) and retinoids to promote normal lung development, in particular during alveolarization. The mechanisms controlling this balance are largely unknown, but recent evidence suggests that midkine (MK), a retinoic acid-regulated, pro-angiogenic growth factor, may function as a critical regulator. The purpose of this study was to examine regulation of MK by GC and RA during postnatal alveolar formation in rats.
\end{abstract}

Methods: Newborn rats were treated with dexamethasone (DEX) and/or all-trans-retinoic acid (RA) during the first two weeks of life. Lung morphology was assessed by light microscopy and radial alveolar counts. MK mRNA and protein expression in response to different treatment were determined by Northern and Western blots. In addition, MK protein expression in cultured human alveolar type 2-like cells treated with DEX and RA was also determined.

Results: Lung histology confirmed that DEX treatment inhibited and RA treatment stimulated alveolar formation, whereas concurrent administration of RA with DEX prevented the DEX effects. During normal development, MK expression was maximal during the period of alveolarization from postnatal day 5 (PN5) to PNI5. DEX treatment of rat pups decreased, and RA treatment increased lung MK expression, whereas concurrent DEX+RA treatment prevented the DEX-induced decrease in MK expression. Using human alveolar type 2 (AT2)-like cells differentiated in culture, we confirmed that DEX and CAMP decreased, and RA increased MK expression.

Conclusion: We conclude that MK is expressed by AT2 cells, and is differentially regulated by corticosteroid and retinoid treatment in a manner consistent with hormonal effects on alveolarization during postnatal lung development. 


\section{Background}

Lung development consists of embryonic, pseudoglandular, canalicular, saccular, and alveolar stages that define a dynamic progression from a rudimentary lung bud to a saccule with a completely developed respiratory tree. The formation of alveoli involves mesenchymal thinning and the development of crests, or secondary septae, at precise sites of the saccular wall. These crests protrude into the saccular air space, include the inner layer of the capillary bilayer, and further subdivide the saccule into subsaccules that later become mature alveoli. The end result is the formation of a complex distal airway structure with a dramatic increase in the surface area available for gas exchange. While not fully understood, the mechanisms regulating secondary septation involve several cell types including endothelial cells, myofibroblasts, and epithelial cells as well as growth factors, hormones, and environmental conditions that either inhibit or stimulate alveolar growth [1].

Lung development in humans reaches its final stage around 35 weeks of gestation, with alveolarization and microvascular maturation continuing postnatally for at least three years if not longer. Lung development in rodents matches that in humans except that alveolarization is entirely a postnatal event, occurring in the first three weeks of life $[2,3]$. This process is associated with decreased plasma corticosteroid concentrations [4], and administration of corticosteroids during this period inhibits alveolarization [5]. Using a neonatal rat model, Massaro and others have demonstrated the effects of dexamethasone (DEX) and all-trans-retinoic acid (RA) treatment on alveolar development. DEX-treated animals develop a simplified architecture with impaired secondary septation and large terminal air sacs, whereas RA-treated animals develop smaller, more numerous alveoli. DEXinduced changes are ameliorated in animals that receive concomitant DEX+RA administration [6].

In rodent models, a precise balance exists between the actions of endogenous GC and retinoids to promote normal lung development, in particular during alveolarization. The mechanisms controlling this balance are largely unknown, but recent evidence suggests that midkine (MK) may function as a critical regulator. $\mathrm{MK}$, a $13 \mathrm{kDa}$ heparin-binding growth factor, is a RA-responsive gene involved in numerous processes including cell migration, tumor progression, inflammation, and angiogenesis. During murine development, $\mathrm{MK}$ expression is widespread early in gestation and becomes restricted to specific sites by late gestation [7]. Further, in the normal developing lung, MK expression increases from PN2, peaks at PN4, and decreases thereafter [8]. In addition, MK has been implicated in mesenchymal thinning in a lung explant culture system [9]. Not affected, however, was branching morphogenesis, a process known to play a key role in the earlier pseudoglandular stage of lung development [9]. Lastly, we have previously shown that $\mathrm{MK}$ is upregulated in glucocorticoid receptor knockout mice, and that GC and RA differentially regulate $\mathrm{MK}$ in vitro [10]. Collectively, these data suggest that $\mathrm{MK}$ is normally decreased in late gestation, corresponding to increased GC and decreased RA signals.

The purpose of this study was to examine regulation of MK expression by GC and RA during postnatal alveolar formation in neonatal rat pups. We hypothesized that MK expression in both lungs and in isolated AT2 cells would be decreased by corticosteroids and increased by RA.

\section{Methods \\ Reagents}

Cell culture media, antibiotics and fetal calf serum were obtained from Invitrogen Inc. (Carlsbad, California). Restriction enzymes, modifying enzymes and other molecular biology reagents were purchased from Promega (Madison, WI), Roche Applied Sciences (Indianapolis, IN) and New England Biolabs Inc. (Beverly, MA). Dexamethasone and 8-bromo-cAMP were purchased from Sigma Chemical Company and ${ }^{35} \mathrm{~S}$-methionine was purchased from Perkin-Elmer Inc. (Boston, MA). All other chemicals were obtained from either Sigma Chemical Company (St. Louis, MO) or Fisher Scientific Inc. (Pittsburgh, PA) unless otherwise specified. H441 and A549 cells were obtained from American Type Culture Collection (Rockville, MD).

\section{Fetal Lung Epithelial Cell and Fibroblast Isolation and Culture}

We isolated enriched populations of epithelial cells from second trimester (1420 wk) human fetal lung tissue obtained from Advanced Bioscience Resources, Inc. (Alameda, CA) under IRB-approved protocols of the Children's Hospital of Philadelphia (CHOP). Epithelial cells were isolated and cultured as previously described [11]. Briefly, after overnight culture as explants [12], the tissue was digested with trypsin, collagenase and DNase, and fibroblasts were removed by differential adherence as described [13]. Non-adherent cells were plated on $60 \mathrm{~mm}$ plastic culture dishes in Waymouth's medium containing $10 \%$ fetal calf serum. After overnight culture (d1), attached cells were cultured an additional 2 days or 4 days in $1 \mathrm{ml}$ of serum-free Waymouth's medium alone (control), or with dexamethasone (DEX, $10 \mathrm{nM}$ ), plus $8-\mathrm{Br}-$ cAMP $(0.1 \mathrm{mM})$ and isobutylmethylxanthine (IBMX, 0.1 $\mathrm{mM}$ ), a combination referred to as DCI, or with DEX or 8Br-cAMP/isobutylmethylxanthine (cAMP) separately. In addition, cultured cells were treated with all-trans-retinoic acid (RA, $5 \mu \mathrm{M}$ ) with or without concomitant DEX, or with RA+CAMP, or with RA+DCI. In previous studies, we 
showed that DCI promotes differentiation of the isolated fetal lung epithelial cells toward a type II cell phenotype. As compared to DCI, Dex or cAMP individually induced only partial type II cell differentiation. In addition, our previous studies have established that epithelial cell purity by this procedure is $83 \pm 2 \%$, with fibroblasts as the primary contaminating cell type [14].

Fibroblasts from the same fetal lung tissue were recovered as the adherent cells during isolation/purification of undifferentiated epithelial cells, allowed to grow for 3 days, then trypsinized and plated for the hormone treatments (1 passage eliminated epithelial cells from the population). After overnight adherence, fibroblasts were cultured for $48 \mathrm{~h}$ in different hormone combinations (DEX or DCI with or without RA).

\section{Animals}

All protocols were reviewed and approved by the CHOP Institutional Animal Care and Use Committee and in accordance with NIH guidelines. Timed pregnant Sprague-Dawley rats (Charles River Breeding Laboratory, Wilmington, MA), were maintained until parturition on a 12:12 h light:dark cycle with unlimited access to food (Purina Lab Diet, St. Louis, MO) and water in the Laboratory Animal Facility at CHOP.

Within 12 hours of birth, litters were adjusted to 10 pups per litter and divided into the following treatment groups: (1) Dexamethasone (DEX, American Regent Laboratories, Inc., Shirley, NY) $0.1 \mu \mathrm{g}$ in $20 \mu \mathrm{l} 0.9 \% \mathrm{NaCl}$ [saline]) or saline alone $(20 \mu \mathrm{l})$ subcutaneously (SQ) daily from PN114; (2) all-trans-retinoic acid (RA, Sigma-Aldrich, St. Louis, MO) $500 \mu \mathrm{g} / \mathrm{kg}$ in $20 \mu \mathrm{l}$ cottonseed oil (CSO, Sigma-Aldrich, St. Louis, MO) or CSO alone $(20 \mu \mathrm{l})$ via intraperitoneal (IP) injection daily from PN3-14; (3) DEX and RA at doses and days as above; (4) saline and CSO at doses and days above; and (5) control (same handling, no injections). The dose of DEX was based on previous literature demonstrating only mild effects on somatic growth [6]. Animals were studied at PN1, 5, 10, and 15. Because it was difficult to discern the gender of rats at birth, both males and females were studied.

\section{Lung Harvest}

Anesthesia for all studies was attained using an intramuscular injection of a Ketamine/Xylazine $(87: 13 \mu \mathrm{g} / \mathrm{kg})$ cocktail. The right lung was removed, snap frozen in liquid nitrogen, and stored at $-80^{\circ} \mathrm{C}$ for future analysis. As previously described [15], the left lung was inflated to 25 $\mathrm{cm} \mathrm{H}_{2} \mathrm{O}$ pressure with formalin and stored in formalin for 24 hours before switching to $70 \%$ alcohol. Water displacement was used to measure lung volume immediately after inflation with maintenance of inflation confirmed by repeat measurement 24 hours after fixation. Lungs were then processed to obtain 5-micron thick paraffin sections. For each time point, sections were stained with hematoxylin and eosin in order to examine lung architectural differences using light microscopy.

\section{Radial alveolar counts (RAC)}

RAC were obtained to quantify alveolarization as previously described [16]. Briefly, a perpendicular line to the edge of the sample was drawn from the center of a bronchial or bronchiolar airway to either the edge of the lung or the nearest connective tissue septum or airway. A minimum of forty lines were drawn for each lung, and the number of septae intersected was counted for each line. In addition, at least three sections from several levels within the tissue block were used for each animal. RAC is a well established method to quantify alveolarization and previous investigators [17] have confirmed that forty measurements per lung are sufficient to establish a reliable morphometric assessment of alveolarization. All RAC calculations were performed using images at $40 \times$ magnification.

\section{Western Blot Analysis}

Western blot analysis was performed using samples obtained from both rat lung tissue and cultured Type II cells using the NOVEX NuPAGE electrophoresis system (Invitrogen) with $1 \mathrm{~mm} \mathrm{412 \%} \mathrm{BisTris} \mathrm{gels} \mathrm{according} \mathrm{to}$ manufacturer's instructions. Briefly, $10 \mu \mathrm{g}$ of lysate was loaded to each well and gels were run at $200 \mathrm{~V}$ at $4{ }^{\circ} \mathrm{C}$ for $50 \mathrm{~min}$ in NuPAGE MOPS SDS running buffer under reducing conditions. Proteins were transferred to nitrocellulose membrane at $30 \mathrm{~V}$ for $60 \mathrm{~min}$ at room temperature. The membrane was then blocked for $1 \mathrm{~h}$ at room temperature with 5\% nonfat dry milk in Tween/Tris-buffered saline (TTBS) (100 mM Tris base, $1.5 \mathrm{M} \mathrm{NaCl}$ adjusted to pH 7.4 with $0.1 \%$ Tween 20 ). The primary antibody, Midkine H-65 (Santa Cruz Biotech, Santa Cruz, CA), was then applied overnight at $4^{\circ} \mathrm{C}$. On the following day, the membrane was washed with TTBS four times, for 10 min each time and a horseradish peroxidase-conjugated goat antirabbit secondary antibody was applied for $1 \mathrm{~h}$ at room temperature. Following this, the membrane was washed with TTBS followed by two 15-min washes with TBS. The blots were developed using a chemiluminescence system (Amersham Pharmacia Biotech, Piscataway, NJ). Equal loading was confirmed by stripping and immunoblotting for $\beta$-actin, which was also used to normalize the data for densitometric analysis. Specificity was also confirmed by probing the blots with normal IgG, which yielded no consistent bands (data not shown).

Semi-quantitative densitometric analysis of bands was accomplished on a Macintosh G3 Power PC computer using MacBAS version 4.2(Fujifilm) after subtraction of background density. Results were calculated as the degree 
of change from control values after normalization to $\beta$ actin densitometry. The results of at least five animals per condition and each time point were expressed as mean \pm SEM and normalized as percent of control.

RNA Isolation Total RNA was obtained from snap-frozen tissue maintained on ice during isolation. Tissue ( $~ 250$ mg wet weight) was mechanically homogenized and total RNA was isolated with RNA Stat-60 reagent (Tel-Test, Friendswood, TX). Purity was verified by measuring the ratio of absorbance at $260 \mathrm{~nm}$ and $280 \mathrm{~nm}$. Quantity and integrity of RNA was measured using the eukaryote total RNA nano assay on an Agilent 2100 bioanalyzer (Agilent, Palo Alto, CA). Integrity was also confirmed using $1 \%$ agarose gels.

\section{Reverse Transcription and Quantitative Real-Time PCR} cDNA was made from total RNA using random primers with SuperScript RT-PCR kit (Invitrogen) following the manufacturer's protocol. Quantitative real-time PCR was performed to assess the induction of Tie 1 mRNA as a marker of endothelial cell content in response to the hormonal treatments. Relative mRNA expression was assessed using polymerase-activated fluorescent PCR probes providing continuous message quantification during amplification (TaqMan, Applied Biosystems, Foster City, CA). Differences in gene expression were determined by comparing the number of PCR cycles required to achieve a threshold of fluorescent activity above background during the exponential phase of the reaction. Sample loading was normalized by the simultaneous amplification of GAPDH. All reactions were performed in triplicate and the average threshold cycle for the triplicate was used in all subsequent calculations. GAPDH primer/ probe set and Tie 1 probe (5'-FAM fluorescent-reporterAGCTGCCTACATCGGAGACGCACC-3') were purchased from Applied Biosystems. Tie 1 forward primer 5'GCCCTTTTAGCCTTGGTGTGT-3', and reverse primer 5'TTCACCCGATCCTGACTGGTA-3' were obtained from Integrated DNA Technologies, Inc. (Coralville, IA).

\section{Northern Blot Analysis}

The membrane was prehybridized for $2 \mathrm{~h}$ at $65^{\circ} \mathrm{C}$ in hybridization solution [0.5 M sodium phosphate, $\mathrm{pH}$ 7.5,7\% SDS, $1 \mathrm{mM}$ EDTA, $1 \%$ BSA, $50 \mu \mathrm{g} / \mathrm{ml}$ poly(A) ${ }^{+}$ RNA, and $50 \mu \mathrm{g} / \mathrm{ml}$ of denatured and sheared salmon sperm DNA]. Midkine cDNA probes were labeled by random priming using the Ready-To-Go Kit (PharmaciaUpjohn) per the manufacturer's instructions and were purified with a G-50 column. The $28 \mathrm{~S}$ oligonucleotide probe was 5 '-end labeled using a 5 '-end-labeling protocol (3550 ng of $28 \mathrm{~S}$ oligonucleotide, $2 \mu \mathrm{l}$ of T4 polynucleotide kinase, and $50 \mu \mathrm{Ci}$ of $\left[\gamma^{-32} \mathrm{P}\right]$ ATP in $1 \times$ kinase buffer) at $37^{\circ} \mathrm{C}$ for $1 \mathrm{~h}$ per the manufacturer's instructions (Promega, Madison, WI). The probe was purified with a
G-25 column (Boehringer Mannheim, Indianapolis, IN). Hybridization of membranes with ${ }^{32}$ P-labeled probes $(1 \times$ $10^{6}$ counts $\cdot \mathrm{min}^{-1} \cdot \mathrm{ml}^{-1}$ ) was performed for $1618 \mathrm{~h}$ at $65^{\circ} \mathrm{C}$. The blots were then washed with saline-sodium citrate- $0.1 \%$ SDS and were developed using a PhosphorImager (Storm 840; Molecular Dynamics, Sunnyvale, CA).

Semi-quantitative densitometric analysis of bands was accomplished on a Macintosh G3 Power PC computer using MacBAS version 4.2(Fujifilm) after subtraction of background density. Results were calculated as the degree of change from control values. The results of at least five animals per condition and each time point was expressed as mean \pm SEM and normalized to percent of control.

\section{Statistical Analysis}

Statistical comparisons between groups were carried out using ANOVA with Fisher's exact test and Bonferroni correction for individual comparisons. All $p$ values less than 0.05 were considered significant.

\section{Results \\ Effects of Hormonal Manipulation on Distal Lung Architecture}

Neonatal rat pups were treated with DEX and/or RA, or appropriate controls, during the first two weeks of life as described in Methods. Representative histology and radial alveolar counts at PN15 is shown in Figure 1. At PN15, DEX-treated animals had larger, simpler distal air spaces than saline controls, with a decreased RAC as compared to control animals $\left({ }^{*} \mathrm{p}<0.05\right)$. These structural changes were evident as early as PN5 (data not shown, see ref. 33). RA-treated pups, on the other hand, had smaller, more numerous alveoli and higher RAC $\left({ }^{* *} \mathrm{p}<0.05\right)$ than CSO controls as early as PN5 and up to PN15. Resolution of corticosteroid-induced changes in architecture was seen between PN10 and 15 in pups treated with concomitant DEX and RA, such that, at PN15, the lungs displayed architecture similar to that of controls and RAC were the same as controls (\# $\mathrm{p}<0.05$ vs. DEX).

Expression of Midkine and Effects of Hormonal Treatment Northern blot analysis was carried out for each treatment group at each time point studied (Figure 2). Data are shown as percent PN1 control levels. Data from the three control groups (no treatment, saline and CSO treatment) were combined since the vehicle treatments had no effect on MK mRNA expression. In control animals, MK mRNA increased between PN5 and PN10. Dexamethasone treatment had a biphasic effect, increasing MK mRNA precociously, between PN1 and PN5, and then decreasing content at PN10 and PN15. RA alone had minimal effects on the developmental pattern. However, with co-treatment, the inhibition observed with dexamethasone was delayed until PN15. 

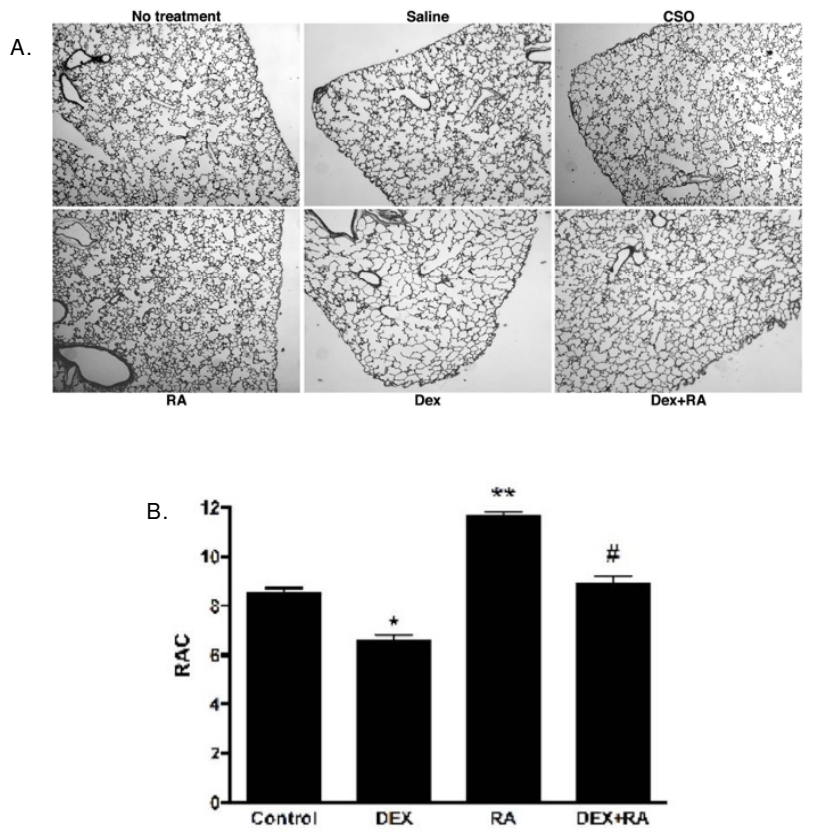

Figure I

Morphologic changes in the lung at PNI 5 after hormonal treatments. (A). A simplified distal architecture was seen in DEX-treated animals. RA-treated animals had smaller and more numerous alveoli. Concomitant DEX and RA administration resulted in septation similar to that of controls. Vehicle (saline or CSO) treatment alone had no effects on lung histology. Control: same handling, no injections. DEX: Dexamethasone. RA: all-trans-retinoic acid. CSO: cottonseed oil. (B). Radial Alveolar Counts confirm the decreased septation seen with DEX treatment $\left({ }^{*} p<0.00\right.$ I DEX vs. control), the increased septation seen with RA $\left({ }^{*} p<\right.$ 0.00 I RA vs. control), and the resolution of DEX effects by concomitant RA administration ( $* * p<0.00$ I DEX vs. DEX+RA). Data are representative of at least 6 rats per treatment group. All images $40 \times$ magnification.

A representative Western blot for $\mathrm{MK}$ is shown in Figure 3 a with a histogram demonstrating densitometric analysis with normalization with $\beta$-actin for equal loading in Figure 3b; $(\beta$-actin blots not shown). In concordance with the known temporal expression patterns of $M K$, protein levels were highest in control animals at PN5, with a 10.5fold induction from PN1, and decreasing thereafter. Dexamethasone treatment delayed the increase in MK with a 3 -fold reduction ( $\mathrm{p}<0.01, \mathrm{n}=3$ ) compared to control animals at PN5. Corresponding to the architecture in RAalone treated lungs, an increase in MK similar to control animals was seen at PN5. This increase was sustained up to PN10 in RA-treated animals being 1.5 fold higher than the same day controls. Concomitant DEX+RA treatment resulted in protein levels similar to those of controls. These data confirmed that no relationship exists between steady state mRNA and protein levels for MK [8].

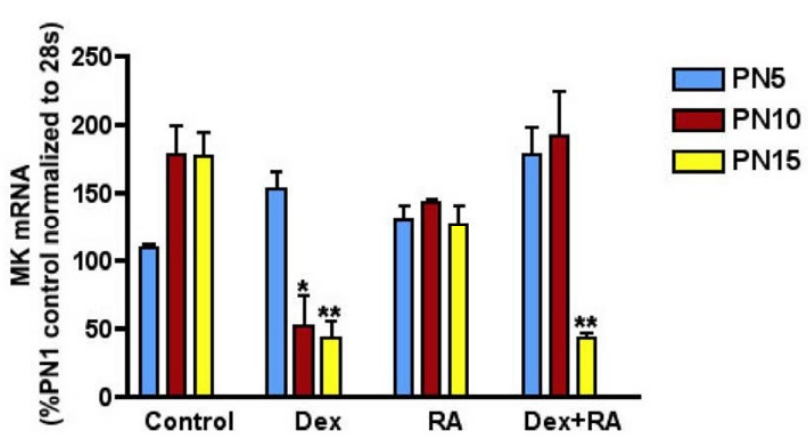

Figure 2

Hormonal regulation of lung MK mRNA expression. mRNA content expressed as percentage of PNI control normalized to $28 \mathrm{~s}$. Data are shown as mean \pm SEM. DEX treatment inhibited and RA treatment had no effect on MK mRNA expression on PNIO and 15. Concomitant RA treatment was unable to restore DEX-induced decrease in MK expression at PNI5 (*p $<0.01$ DEX vs. control at PNI0, **p $<0.00$ I DEX or DEX+RA vs. control at PNI5).

\section{Changes in Tiel expression during hormonal treatment partially correlated with the changes in MK expression and lung morphology}

MK plays a significant role in angiogenesis. We therefore wanted to test if Tie1, a marker of endothelial cells, would change during hormonal treatment and correlate with the changes in MK. Expression of Tie1 mRNA was determined by real Time RT-PCR ( $\mathrm{n}=49$ per group). As shown in Figure 4, Tie1 expression was significantly decreased in DEXtreated animals at both PN10 and 15 compared to control ( ${ }^{*} P=0.0006$ and 0.0022 respectively). At PN5, there was a trend toward decreased Tie 1 expression with DEX and increased Tie1 expression when RA was added to DEX treatment. However, this did not reach statistical significance $(p=0.08)$. RA treatment alone did not change Tie 1 expression and also failed to restore DEX-induced decrease in Tie 1 expression at PN10 and 15 (RA+DEX vs. control: ${ }^{*} p=0.04$ at PN10 and ${ }^{*} p=0.01$ at PN15).

\section{Hormonal Regulation of $M K$ in ATII-like Cells}

We next examined the expression and hormonal regulations of $\mathrm{MK}$ in isolated human alveolar epithelial cells and fibroblasts. We used a well-established method of alveolar epithelial cell isolation and culture. DCI promotes the differentiation of isolated undifferentiated epithelial cells towards a type II epithelial cell phenotype. In the same system, DEX or cAMP alone induces only partial differentiation. We therefore examined the effect of different hormone combinations on MK expression.

Western blot analysis of MK regulation in Type II-like cells and lung fibroblasts are shown in Figure 5. The levels of 
A.
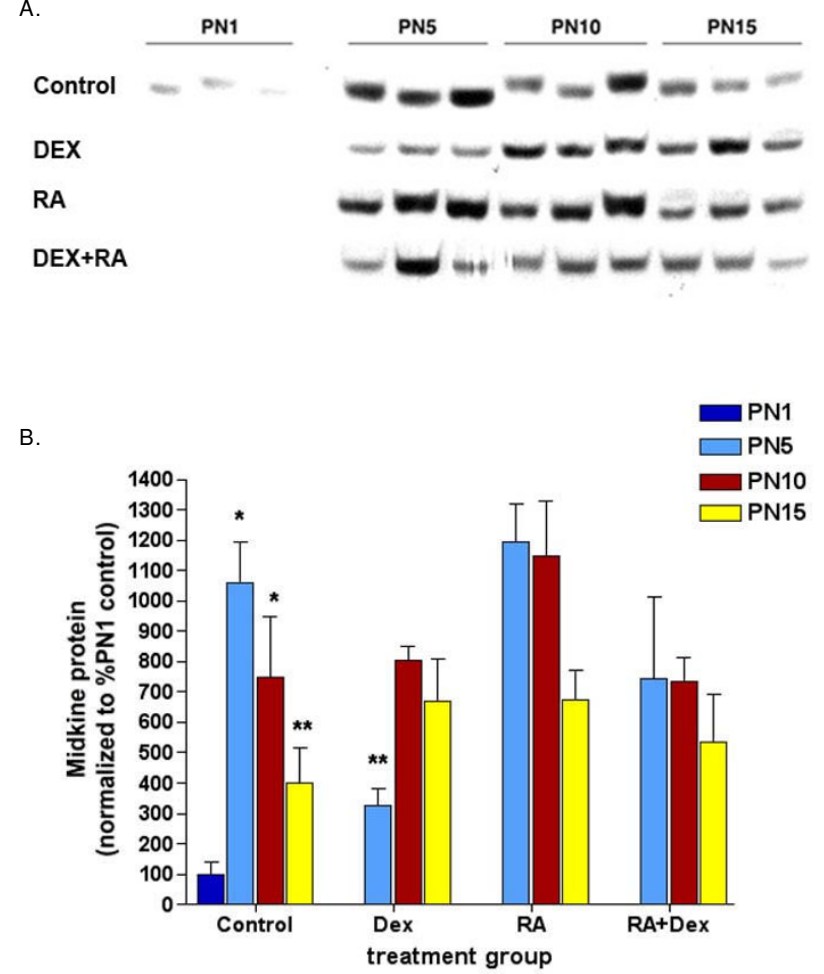

Figure 3

Hormonal regulation of lung MK protein. A) Representative Western blots of MK expression in neonatal rat lungs after various treatments. B) Densitometry analysis confirmed that, in control animals, MK protein content was highest at PN5, with a 10.5-fold induction from day I $\left(^{*} p<0.0 \mathrm{I}\right.$, $\mathrm{n}=3)$, and decreased thereafter $(* * p=0.02$ PN5 control vs. PNI 5 control, $n=3$ /group). In contrast, MK was significantly decreased in DEX-treated lungs at PN5 with a 3-fold reduction compared to the same day control animals $(* * p<0.01, n$ =3). An increase in MK similar to control animals was seen at PN5, but this increase was sustained up to PNIO in RAtreated animals being $I .5$ fold higher than PNI 0 controls. Concomitant DEX+RA treatment resulted in a return of protein levels to that of control.

MK protein expression with various treatments were similar on PN3 and PN5. Therefore, combined densitometry data are shown in figure $5 \mathrm{~B}$. MK expression increased 10fold during cell culture without hormones or serum. Cells treated with hormones (DEX, CAMP, or DCI) had significantly decreased $M K$ protein levels, with an apparent additive effect of GC and CAMP to repress the cultureinduced increase in $\mathrm{MK}$ and RA eliminated the repressive effects of hormones $\left({ }^{* *} p<0.05\right.$ vs. no RA).

Fetal lung fibroblast had minimal MK expression with or without hormone treatment (Figure 5c), whereas ATII-like cells showed much more robust MK expression especially

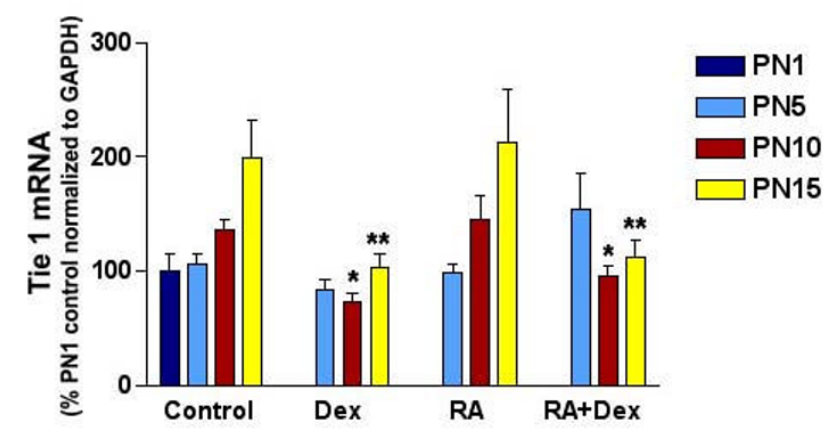

Figure 4

Tie I mRNA expression during hormonal treatment. mRNA content expressed as percentage of control normalized to GAPDH. Data are shown as mean \pm SEM $(n=49$ group). DEX treatment significantly decreased Tiel expression at both 10 and 15 days $\left(* p=0.0006\right.$ and ${ }^{*} * p=0.0022$ respectively) as compared to same days controls. RA treatment alone did not change Tie I expression and also failed to restore DEX-induced decrease in Tie I expression (* and **p $=0.04$ ).

in the presence of RA. These data suggest that alveolar epithelial cells, and not fibroblasts, are the primary source of MK.

\section{Discussion}

In the present study, we show that, in normal lungs, midkine $(\mathrm{MK})$ protein content is highest at PN5, and begins to decline by PN10. This finding is in concordance with Matsuura et al. who showed a transient increase in $\mathrm{MK}$ expression in normal lungs between two to seven days postnatally [8]. We extend these observations to demonstrate that, in vivo, GC treatment is associated with lower and RA treatment with higher lung MK protein expression. However, in our hands, changes in steady state $\mathrm{MK}$ mRNA did not match MK protein expression after hormonal treatments. Hormonally driven changes in protein expression were also seen in cultured human type II-like epithelial cells, but not fibroblasts, isolated from second trimester human fetal lung tissue.

The regulation of the balance between the actions of GC and RA on lung development is largely unknown. Studies by Kaplan et al have suggested that MK might serve as a potential bridge between these two systems [18]. MK is a retinoic acid-responsive, heparin binding growth factor that promotes angiogenesis, cell growth, and cell migration $[19,20]$. A bimodal temporal-spatial expression pattern of $\mathrm{MK}$ is seen in the developing mouse lung. High levels of $\mathrm{MK}$ expression are observed at embryonic day (E)13-16.5 and then again at postnatal days 512, primarily in respiratory epithelium early in lung development and increasingly localized to lung stroma and pulmonary 
A.

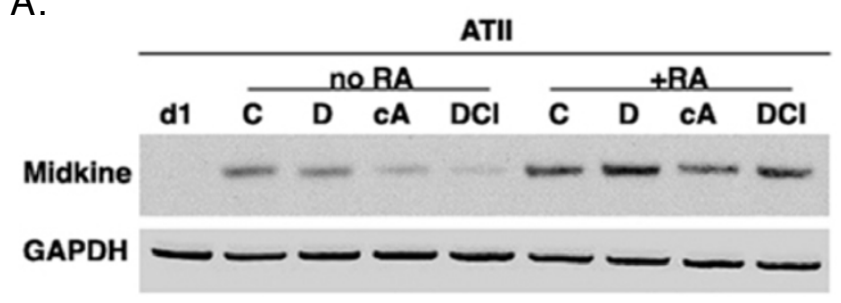

C.

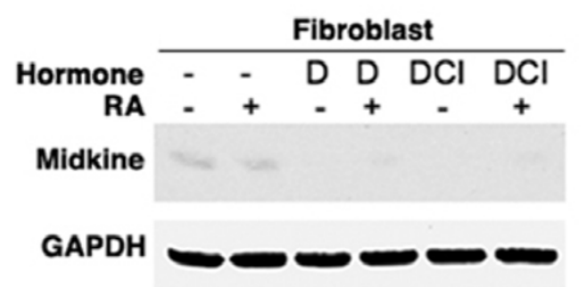

B.

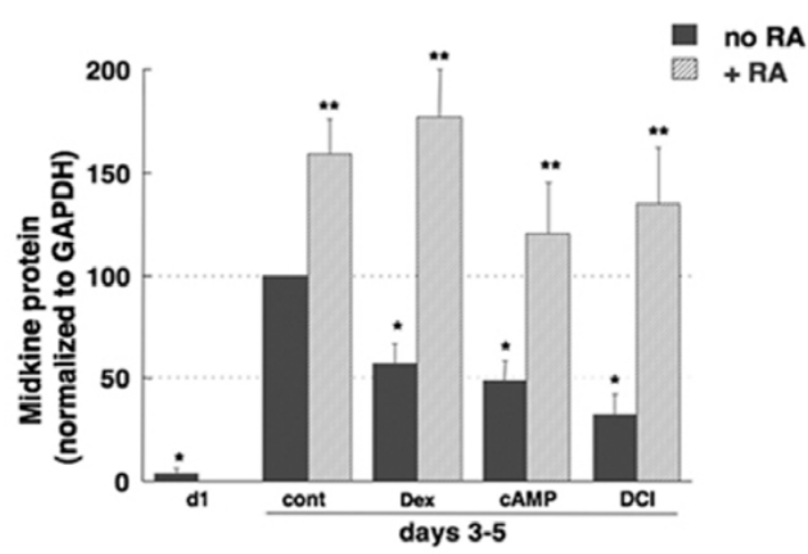

\section{Figure 5}

Hormonal regulation of $M K$ in isolated human Type II-like cells. A) Representative western blot and B) Densitometry analysis of MK expression in human fetal alveolar epithelial cells treated with different hormone combination: Alveolar epithelial cells obtained from second trimester human fetal lung tissue treated with hormones (DEX, cAMP and IBMX, or DCl) to differentiate them into alveolar type II (ATII) cells have significantly decreased MK protein content at day 3 and day 5 as compared to controls with no treatment $\left({ }^{*} p<0.01\right)$. However, RA treatment alone or concomitant RA treatment with hormones was associated with significant increase in MK protein expression $(* * p<0.05)$. C) Fetal lung fibroblasts isolated from the same second trimester human fetal lung tissue were treated with DEX or DCI with/or without RA. Expression of MK was very low irrespective of treatment groups. GAPDH expression was used as a loading control.

blood vessels postnatally [21]. However, its expression is completely absent from the adult mouse lung. These findings suggest that MK may be involved in epithelial differentiation, vascular growth and remodeling in the developing lung and is not required for regular lung maintenance.

Although MK was initially identified as a retinoic acidresponsive gene, mechanisms regulating its expression in the lung have not been fully understood. Examples of these MK regulators include thyroid transcription factor (TTF)-1 [22], and hypoxia-inducible factor (HIF)-1 [23]. Through gene array analysis of GC receptor knockout mice, Kaplan et al demonstrated that $\mathrm{MK}$ is dynamically regulated by both GC and retinoic acid during normal fetal lung development [10]. While these observations provided a potential mechanism for the integration of GC and retinoid effects in late gestation fetal lung development, whether GC and RA also influence MK gene expression during postnatal lung development remained unknown. In this study, we found that GC treatment induced an early suppression of MK protein expression at PN5, whereas RA treatment was associated with higher and persistent $\mathrm{MK}$ expression to PN10 in neonatal rats. This regulatory pattern of MK expression by GC and RA is even clearer in the isolated human fetal lung epithelial cells. Collectively, our data suggest that MK is likely differ- entially regulated by GC and RA from the late saccular to early alveolar stage of lung development.

Prolonged treatment with high doses of GC was widely used in immature infants with evolving bronchopulmonary dysplasia (BPD) during the 1990s. These treatments were based on the belief that such treatment was associated with less early postnatal lung inflammation and a reduction in the incidence of BPD among premature infants [24]. However, subsequent clinical trials of DEX treatment, beginning at 24 weeks after birth, failed to demonstrate differences in ventilation requirements or incidence of BPD, and showed toxic effects including increased risk of infection, hyperglycemia and abnormal neurodevelopmental outcome in exposed patients [2527]. These toxic effects of high-dose steroids have also been documented in animal studies [28,29]. Further, there is evidence from rodent studies that postnatal steroid treatment also inhibits alveolarization and reduces lung growth [30]. The serum concentration of GC reaches a nadir during the period of maximum secondary septation, whether prenatal or postnatal, and increases as septation ends [4,31]. This suggests that endogenous corticosteroids might be inhibitors of septation. Indeed, our present study shows that treatment with DEX results in simplified distal lung architecture with reduced secondary septation in neonatal rats. These results are in agree- 
ment with the findings of Blanco et al [32] and our previous studies [33].

The mechanism(s) by which DEX inhibits septation is not well understood, but may be related to the inhibitory effect of GC on DNA synthesis and cell proliferation [34]. Discontinuing corticosteroids after the "critical period" of alveolarization is not followed by spontaneous septation. The process of alveolar septation requires active replication of epithelial and other cells. GC therefore might prevent septation via its ability to inhibit cell division $[5,34]$. In addition, this failed septation is accompanied by a reduced number of pulmonary arteries and a restricted alveolar capillary bed [35]. Our results demonstrating decreased Tie1 expression with DEX treatment further support these findings.

Several lines of evidence have indicated that retinoids might be important regulators of alveolarization. Initial evidence was provided by Brody et al. who reported that fibroblasts rich in vitamin A storage granules form a large fraction of the alveolar wall during septation [36,37]. These lipid-rich fibroblasts play a key role in producing elastin at the sites of new secondary septa $[38,39]$. Retinoids signal through their receptors, RARs and RXRs. Indeed, deletion or inhibition of RAR results in reduced elastin and alveolar simplification [40,41]. Studies by Massaro et al have shown that RA treatment results in increased septation in newborn rats and also induces alveoli formation in adult rats with elastase-induced emphysema $[42,43]$. In humans, low levels of vitamin A have been found in premature babies at risk for BPD and vitamin A supplementation reduces the incidence of BPD in these babies [44,45]. Consistent with these studies, and providing a potential mechanism by which retinoids might decrease the incidence of BPD, we show that animals receiving retinoic acid (RA) treatment had smaller and more numerous alveoli and that concomitant treatment with DEX and RA prevented the DEX-induced changes in septation.

Closely linked to the development of distal alveolar structures is the formation of a mature vascular plexus [46]. The transition from saccular to alveolar stages of lung development correlates with microvascular development and allows for close apposition of the vascular bed and airspace for efficient gas exchange to occur [44]. The molecular signals that link these two processes are not clear. However, a complex interplay of epithelialendothelial cells is most likely required for normal lung morphogenesis. Recently, the "vascular hypothesis" of BPD [47] has proposed that inhibition of vascular growth itself may directly impair alveolarization. Several observations support the importance of vascular formation as vital for normal alveolar development. For example, treatment of neonatal rat pups with anti-angiogenic drugs, such as thalidomide, or VEGF receptor blocker is associated with a simplified distal lung architecture and decreased vascularization [48]. In addition, FGF receptor 3 and 4 double knockout mice fail to develop a mature distal lung architecture [49]. Further, decreased endothelial cell migration by blocking anti-PECAM-1 antibody or in PECAM-1 null mice is associated with disrupted alveolarization [50]. In humans, an abnormal alveolar capillary network and decreased expression of endothelial cell markers have been found in premature newborns dying with BPD [51]. The fact that GC treatment decreased MK expression both in vivo and in cultured type II lung epithelial cells, (as demonstrated by the current study), and also decreased Tie1 expression on PN10 and 15, suggests that GC might inhibit alveolarization by interfering with epithelial-endothelial communication via $\mathrm{MK}$ and altering normal alveolar septal vascular development. However, RA treatment had no effect on Tie1 expression and also failed to rescue the decreased Tie 1 expression caused by DEX-treatment in our study. This suggests that the RAinduced enhancement in septation and the rescue of GCinduced inhibition of alveolarization may not be mediated by affecting endothelial content.

\section{Conclusion}

In summary, we have demonstrated that MK is differentially regulated by corticosteroid and retinoid treatment during postnatal lung development, and that its expression matches the hormonal effects on alveolarization. MK may, therefore, serve as a paracrine signal that originates in the epithelium, targets pulmonary vascular cells and influences lung vascularization during the alveolar and microvascular maturation phase of lung development.

\section{Competing interests}

The authors declare that they have no competing interests.

\section{Authors' contributions}

$\mathrm{HZ}$ was responsible for part of the animal studies, performing statistical analyses, performing real-rime PCR analysis, and drafting the manuscript. SJG was responsible for some animal studies and measuring radial alveolar counts. ZC performed the Northern and Western blots for MK from the animal samples. JPF, MJ and GSM assisted in animal harvesting and injections, as well as some data analysis. FK and NBS helped conceive the study and design initial experiments. LWG was responsible for the determination of MK expression in alveolar type II cells and fibroblasts. RCS conceived the study, participated in its design and coordination, and helped to write and revise the manuscript. All authors read and approved the final manuscript. 


\section{Acknowledgements}

The experiments in this study were supported by NIH grants HL07930, HL079090 and HL073896 to RCS. HZ was funded by the NIH Pediatric Scientist Development Award (HD00850) and RCS holds the William Buchanan Chair in Pediatrics at University of Texas Southwestern Medical Center. We thank Dr. Philip L. Ballard for multiple discussions and critical review of the manuscript.

\section{References}

I. Massaro GD, Massaro D: Formation of pulmonary alveoli and gas-exchange surface area: quantitation and regulation. Annu Rev Physiol 1996, 58:73-92.

2. Burri PH: The postnatal growth of the rat lung. 3. Morphology. Anat Rec 1974, I 80(1):77-98.

3. Burri PH, Dbaly J, Weibel ER: The postnatal growth of the rat lung. I. Morphometry. Anat Rec 1974, 178(4):7II-730.

4. Henning S): Plasma concentrations of total and free corticosterone during development in the rat. Am J Physiol 1978, 235(5): E45।-456.

5. Massaro D, Teich N, Maxwell S, Massaro GD, Whitney P: Postnatal development of alveoli: Regulation and evidence for a critical period in rats. J Clin Invest 1985, 76: | 297- 1305.

6. Massaro GD, Massaro D: Postnatal treatment with retinoic acid increases the number of pulmonary alveoli in rats. Am J Physiol 1996, 270:L305-L310.

7. Kadomatsu K, Huang RP, Suganuma T, Murata F, Muramatsu T: A retinoic acid responsive gene MK found in the teratocarcinoma system is expressed in spatially and temporally controlled manner during mouse embryogenesis. J Cell Biol 1990, I I 0(3):607-616.

8. Matsuura O, Kadomatsu K, Takei Y, Uchimura K, Mimura S, Watanabe $K$, Muramatsu T: Midkine expression is associated with postnatal development of the lungs. Cell Struct Funct 2002, 27(2): 109-II5.

9. Toriyama K, Muramatsu H, Hoshino T, Torii S, Muramatsu T: Evaluation of heparin-binding growth factors in rescuing morphogenesis of heparitinase-treated mouse embryonic lung explants. Differentiation 1997, 6 I(3): 161-167.

10. Kaplan F, Comber J, Sladek R, Hudson TJ, Muglia LJ, Macrae T, Gagnon S, Asada M, Brewer JA, Sweezey NB: The growth factor midkine is modulated by both glucocorticoid and retinoid in fetal lung development. Am J Respir Cell Mol Biol 2003, 28(I):33-4I.

II. Gonzales LW, Angampalli S, Guttentag SH, Beers MF, Feinstein SI, Matlapudi A, Ballard PL: Maintenance of differentiated function of the surfactant system in human fetal lung type II epithelial cells cultured on plastic. Pediatr Pathol Mol Med 200I, 20(5):387-4I2.

12. Gonzales LW, Ballard PL, Ertsey R, Williams MC: Glucocorticoids and thyroid hormones stimulate biochemical and morphological differentiation of human fetal lung in organ culture. J Clin Endocrinol Metab 1986, 62(4):678-69।.

13. Ballard PL, Ertsey R, Gonzales LK, Liley HG, Williams MC: Isolation and characterization of differentiated alveolar type II cells from fetal human lung. Biochim Biophys Acta 1986, 883(2):335-344.

14. Gonzales LW, Guttentag SH, Wade KC, Postle AD, Ballard PL: Differentiation of human pulmonary type II cells in vitro by glucocorticoid plus CAMP. Am J Physiol Lung Cell Mol Physiol 2002, 283(5):L940-95I.

15. Savani RC, Godinez RI, Godinez MH, Wentz E, Zaman A, Cui Z, Pooler PM, Guttentag SH, Beers MF, Gonzales LW, et al.: Respiratory distress after intratracheal bleomycin: selective deficiency of surfactant proteins B and C. Am J Physiol Lung Cell Mol Physiol 200I, 28I:L685-L696.

16. Emery JL, Mithal A: The number of alveoli in the terminal respiratory unit of man during late intrauterine life and childhood. Arch Dis Child 1960, 35:544-547.

17. Cooney TP, Thurlbeck WM: The radial alveolar count method of Emery and Mithal: a reappraisal I postnatal lung growth. Thorax 1982, 37(8):572-579.

18. Morrisey EE, Savani RC: Midkine: a potential bridge between glucocorticoid and retinoid effects on lung vascular development. Am J Respir Cell Mol Biol 2003, 28(I):5-8.
19. Muramatsu H, Muramatsu T: Purification of recombinant midkine and examination of its biological activities: functional comparison of new heparin binding factors. Biochem Biophys Res Commun I99I, 177(2):652-658.

20. Takada T, Toriyama K, Muramatsu H, Song XJ, Torii S, Muramatsu T: Midkine, a retinoic acid-inducible heparin-binding cytokine in inflammatory responses: chemotactic activity to neutrophils and association with inflammatory synovitis. J Biochem 1997, I 22(2):453-458.

21. Mitsiadis TA, Salmivirta M, Muramatsu T, Muramatsu $\mathrm{H}$, Rauvala $\mathrm{H}$, Lehtonen E, Jalkanen M, Thesleff I: Expression of the heparinbinding cytokines, midkine (MK) and HB-GAM (pleiotrophin) is associated with epithelial-mesenchymal interactions during fetal development and organogenesis. Development 1995, I 2 I(I):37-5I.

22. Reynolds PR, Mucenski ML, Whitsett JA: Thyroid transcription factor (TTF) - I regulates the expression of midkine (MK) during lung morphogenesis. Dev Dyn 2003, 227(2):227-237.

23. Reynolds PR, Mucenski ML, Le Cras TD, Nichols WC, Whitsett JA: Midkine is regulated by hypoxia and causes pulmonary vascular remodeling. J Biol Chem 2004, 279(35):37| 24-37I32.

24. Yeh TF, Lin YJ, Hsieh WS, Lin HC, Lin CH, Chen JY, Kao HA, Chien $\mathrm{CH}$ : Early postnatal dexamethasone therapy for the prevention of chronic lung disease in preterm infants with respiratory distress syndrome: a multicenter clinical trial. Pediatrics 1997, 100(4):E3.

25. Papile LA, Tyson JE, Stoll BJ, Wright LL, Donovan EF, Bauer CR, Krause-Steinrauf $H$, Verter J, Korones SB, Lemons JA, et al.: A multicenter trial of two dexamethasone regimens in ventilatordependent premature infants. $N$ Engl J Med 1998, 338(16): IIII2-III8.

26. Yeh TF, Lin YJ, Huang CC, Chen YJ, Lin CH, Lin HC, Hsieh WS, Lien YJ: Early dexamethasone therapy in preterm infants: a follow-up study. Pediatrics 1998, I 0 I(5):E7.

27. O'Shea TM, Kothadia JM, Klinepeter KL, Goldstein DJ, Jackson BG, Weaver RG 3rd, Dillard RG: Randomized placebo-controlled trial of a 42-day tapering course of dexamethasone to reduce the duration of ventilator dependency in very low birth weight infants: outcome of study participants at I-year adjusted age. Pediatrics 1999, 104:15-2I.

28. Flagel SB, Vazquez DM, Watson SJ Jr, Neal CR Jr: Effects of tapering neonatal dexamethasone on rat growth, neurodevelopment, and stress response. Am J Physiol Regul Integr Comp Physiol 2002, 282(I):R55-63.

29. Edwards HE, Burnham WM: The impact of corticosteroids on the developing animal. Pediatr Res 200I, 50(4):433-440.

30. Blanco $L N$, Frank $L$ : The formation of alveoli in rat lung during the third and fourth postnatal weeks: effect of hyperoxia, dexamethasone, and deferoxamine. Pediatr Res 1993, 34(3):334-340.

31. Jones CT: Corticosteroid concentrations in the plasma of fetal and maternal guinea pigs during gestation. Endocrinology 1974 , 95(4): I I29-1 I33.

32. Blanco LN, Massaro GD, Massaro D: Alveolar dimensions and number: developmental and hormonal regulation. Am J Physiol 1989, 257:L240-247.

33. Garber SJ, Zhang H, Foley JP, Zhao H, Butler SJ, Godinez RI, Godinez $\mathrm{MH}$, Gow AJ, Savani RC: Hormonal regulation of alveolarization: structure-function correlation. Respir Res 2006, 7:47.

34. Loeb JN: Corticosteroids and growth. N Engl J Med 1976, 295( (10):547-552.

35. Le Cras TD, Kim DH, Gebb S, Markham NE, Shannon JM, Tuder RM, Abman SH: Abnormal lung growth and the development of pulmonary hypertension in the Fawn-Hooded rat. Am J Physiol 1999, 277(4 Pt I):L709-7I8.

36. Maksvytis HJ, Vaccaro C, Brody JS: Isolation and characterization of the lipid-containing interstitial cell from the developing rat lung. Lab Invest 1981, 45(3):248-259.

37. Brody JS, Kaplan NB: Proliferation of alveolar interstitial cells during postnatal lung growth. Evidence for two distinct populations of pulmonary fibroblasts. Am Rev Respir Dis 1983, I 27(6):763-770.

38. Okabe T, Yorifuji H, Yamada E, Takaku F: Isolation and characterization of vitamin-A-storing lung cells. Exp Cell Res 1984, I54(I): 125-135. 
39. McGowan SE, Harvey CS, Jackson SK: Retinoids, retinoic acid receptors, and cytoplasmic retinoid binding proteins in perinatal rat lung fibroblasts. Am J Physiol 1995, 269(4 Pt I):L463-472.

40. Massaro GD, Massaro D, Chambon P: Retinoic acid receptoralpha regulates pulmonary alveolus formation in mice after, but not during, perinatal period. Am J Physiol Lung Cell Mol Physiol 2003, 284(2): L43I-433.

4I. Yang L, Naltner A, Yan C: Overexpression of dominant negative retinoic acid receptor alpha causes alveolar abnormality in transgenic neonatal lungs. Endocrinology 2003, | 44(7):3004-30II.

42. Massaro GD, Massaro $D$ : Retinoic acid treatment partially rescues failed septation in rats and in mice. Am J Physiol Lung Cell Mol Physiol 2000, 278(5):L955-960.

43. Massaro D, Massaro GD: Pulmonary alveolus formation: critical period, retinoid regulation and plasticity. Novartis Found Symp 200I, 234:229-236. discussion 23624I

44. Shenai JP, Chytil F, Jhaveri A, Stahlman MT: Plasma vitamin A and retinol-binding protein in premature and term neonates. I Pediatr 198I, 99(2):302-305.

45. Tyson JE, Wright LL, Oh W, Kennedy KA, Mele L, Ehrenkranz RA, Stoll B], Lemons JA, Stevenson DK, Bauer CR, et al.: Vitamin A supplementation for extremely-low-birth-weight infants. National Institute of Child Health and Human Development Neonatal Research Network. N Engl J Med 1999, 340(25): 1962-1968.

46. Burri PH: Fetal and postnatal development of the lung. Annu Rev Physiol 1 984, 46:61 7-628.

47. Abman SH: Bronchopulmonary dysplasia: "a vascular hypothesis". Am J Respir Crit Care Med 200I, I64(I0 Pt I): 1755-I756.

48. Jakkula M, Le Cras TD, Gebb S, Hirth KP, Tuder RM, Voelkel NF, Abman $\mathrm{SH}$ : Inhibition of angiogenesis decreases alveolarization in the developing rat lung. Am J Physiol Lung Cell Mol Physio 2000, 279(3):L600-607.

49. Weinstein $M, X u$ X, Ohyama K, Deng CX: FGFR-3 and FGFR-4 function cooperatively to direct alveogenesis in the murine lung. Development 1998, I 25( I8):3615-3623.

50. DeLisser HM, Helmke BP, Cao G, Egan PM, Taichman D, Fehrenbach M, Zaman A, Cui Z, Mohan GS, Baldwin HS, et al.: Loss of PECAMI function impairs alveolarization. J Biol Chem 2006, 28 I (I3):8724-873|.

5I. Bhatt AJ, Pryhuber GS, Huyck H, Watkins RH, Metlay LA, Maniscalco WM: Disrupted pulmonary vasculature and decreased vascular endothelial growth factor, FIt-I, and TIE-2 in human infants dying with bronchopulmonary dysplasia. Am J Respir Crit Care Med 200I, I64(I0 Pt I): | 97|-1980.

Publish with Bio Med Central and every scientist can read your work free of charge

"BioMed Central will be the most significant development for disseminating the results of biomedical research in our lifetime. "

Sir Paul Nurse, Cancer Research UK

Your research papers will be:

- available free of charge to the entire biomedical community

- peer reviewed and published immediately upon acceptance

- cited in PubMed and archived on PubMed Central

- yours - you keep the copyright
BioMedcentral 